\title{
Mass fluxes of xenobiotics below cities: challenges in urban hydrogeology
}

\author{
Mario Schirmer • Frido Reinstorf - Sebastian Leschik • Andreas Musolff • Ronald Krieg • \\ Gerhard Strauch · John W. Molson • Marion Martienssen • Kristin Schirmer
}

Received: 7 June 2010/Accepted: 16 November 2010/Published online: 4 December 2010

(C) Springer-Verlag 2010

\begin{abstract}
Urban areas are the focus of major ecological, social and economical activity. They are thus also prime locations of increasing conflict with regard to water use and water protection. As a direct and/or indirect consequence of urban land use and human activity, urban water systems are frequently polluted with organic contaminants including waste water-born xenobiotics such as pharmaceuticals, personal care products (collectively known as PPCPs) and endocrine-active substances. This study reviews new integrated methodologies including flux calculations as well as chemical investigations for determining the impact of
\end{abstract}

human activities on urban water systems and on processes within the urban watershed. The use of indicator substances, representing different contaminant sources and pathways, integral pumping tests and mass balance approaches are suitable alternatives within these environments. The issues are explored using contaminant mass balance examples from Halle/Saale and Leipzig, Germany.

Keywords Leaky sewers - Mass balance . Micropollutants · PPCP · Urban groundwater · Urban hydrogeology

\footnotetext{
M. Schirmer ( $ه)$

Ueberlandstr. 133, 8600 Duebendorf, Switzerland

e-mail: mario.schirmer@eawag.ch

F. Reinstorf

Department of Water and Waste Management,

University of Applied Sciences Magdeburg-Stendal, Breitscheidstr. 2, 39114 Magdeburg, Germany

e-mail: frido.reinstorf@hs-magdeburg.de

S. Leschik

Department of Groundwater Remediation, UFZ,

Helmholtz Centre for Environmental Research,

Permoserstr. 15, 04318 Leipzig, Germany

e-mail: sebastian.leschik@ufz.de

A. Musolff · G. Strauch

Department of Hydrogeology, UFZ,

Helmholtz Centre for Environmental Research,

Permoserstr. 15, 04318 Leipzig, Germany

e-mail: andreas.musolff@ufz.de

G. Strauch

e-mail: gerhard.strauch@ufz.de
}

Department of Water Resources and Drinking Water, Eawag,

Swiss Federal Institute of Aquatic Science and Technology,

\author{
R. Krieg \\ Department of Hydrogeology, UFZ, \\ Helmholtz Centre for Environmental Research, \\ Theodor-Lieser-Str. 4, 06120 Halle/Saale, Germany \\ e-mail: ronald.krieg@ufz.de

\section{J. W. Molson} \\ Department of Geology and Geological Engineering, \\ Laval University, Quebec City, Quebec G1V0A6, Canada \\ e-mail: john.molson@ggl.ulaval.ca
}

\section{Martienssen}

Chair Biotechnology of Water Treatment,

Institute for Environmental Technology,

Brandenburg University of Technology Cottbus,

Siemens-Halske-Ring 8, 03046 Cottbus, Germany

e-mail: marion.martienssen@tu-cottbus.de

\section{K. Schirmer}

Department of Environmental Toxicology, Eawag,

Swiss Federal Institute of Aquatic Science and Technology,

Ueberlandstr. 133, 8600 Duebendorf, Switzerland

e-mail: kristin.schirmer@eawag.ch 


\section{Introduction}

Half of the world's population and about $73 \%$ of Europeans live in cities. In addition, about $82 \%$ of global population growth currently occurs in cities of the developing countries (UN 2004). Consumption of land by increasing urban sprawl and associated anthropogenic activity is seriously degrading urban water quality and quantity. In particular, the pollution of urban water systems by diffusive and direct contribution from waste water sources is of growing concern (Schwarzenbach et al. 2006). In this regard, an integral view on urban water resources is needed since both surface water and groundwater resources are affected by waste water input. For example, urban surface water may be degraded by effluent discharge from waste water treatment plants or by combined sewer overflows (CSOs). Groundwater may be deteriorated by waste water losses from leaky sewers. The pollution of groundwater resources is of special concern since xenobiotics can persist over several decades, leading to sustained contamination. The challenge in assessing the contamination of urban water resources lies in interpreting the complex spatial-temporal interaction of groundwater and surface water with the sewage system and the resulting heterogeneity of xenobiotic loads and concentrations (Musolff 2009).

Our past research on urban water supplies in Leipzig and Halle/Saale (Germany) focused on the source, distribution and transport behaviour of xenobiotics as indicator targets for assessing the anthropogenic impact on the urban water system (Strauch et al. 2008). The xenobiotics considered in that study were micropollutants including pharmaceuticals, personal care products (collectively referred to as PPCPs) and industrial chemicals, which show low concentrations in urban waters and are a direct and/or indirect consequence of human activity (Schirmer and Schirmer 2008). An increasing number of PPCPs are being found in urban water systems and drinking water (e.g., Ternes 1998; Heberer 2002). Since the number of prescriptions generally rises with increasing age and as people are living longer, it can be assumed that we will face an increasing input of pharmaceuticals into the urban water cycle.

With regard to toxicological effects, several studies have already shown that as yet unknown eco-toxicological impacts due to the presence of PPCPs may exist (Luckenbach and Epel 2005; Schmitt-Jansen et al. 2007). The potential long-term effects of such compounds in the ecosystem and in humans, as well as their fate in the environment, are also widely unknown (Schwarzenbach et al. 2006). Thus, an emerging field of scientific and engineering research is focussing on the safe disposal of increasing amounts of waste water without endangering ecosystems and future water usage.
Within the perspective of xenobiotic risk assessment, we also need to provide xenobiotic exposure scenarios for the urban receiving water resources. This approach should incorporate sound knowledge on both the xenobiotic concentration variability as well as on the xenobiotic mass fluxes in urban watersheds. While concentration variability in time and space provides valuable information for toxicological assessments of the receiving ecosystems, mass flux estimations allow the assessment of long-term trends and can be more useful for relating total impact loading with respect to the city's size, the number of inhabitants and the density and condition of the sewer network.

The goal of this paper is to (1) summarize the unique characteristics (relevant to xenobiotic measurements) which exist in urban hydrogeological settings, (2) identify which indicators can be used to assess PPCP contamination and (3) to determine which investigation and monitoring techniques can be used.

The unique conditions within urban watersheds require new methodologies for assessing the impact of human activities and to identify the relevant physical processes. To this end, we have used different approaches in relation to the hydrogeological and hydrodynamic environment of the cities of Leipzig and Halle/Saale (Germany). For the urban area of Halle, a flow and transport model was developed based on the interaction between surface water of the Saale River and groundwater. In the city of Leipzig, we established a monitoring program that allowed detailed studies on the distribution of xenobiotics and their pathways between waste water, surface water and groundwater. Multivariate statistics and integral pumping tests (IPTs) were applied to account for the highly heterogeneous conditions and time-varying concentrations. At both sites, we demonstrated the use of indicator targets consisting of inorganic major ions, isotopes and compound-specific patterns of xenobiotics.

\section{Unique hydrogeological characteristics in urban areas}

\section{Subsurface environment}

Heterogeneous geology, ground surface sealing and extensive subsurface infrastructure are common characteristics of many urban areas (Lerner, 2002). As a consequence, surface water and groundwater water quality and quantity as well as groundwater recharge can be affected. For example, building structures, electrical, transportation and communication systems and complex water supply and sewer networks, often extend into the groundwater zone. Via such complex pathways, contaminants can be introduced from shallow or ground surface sources into the subsurface and further into the groundwater. Primary 
sources of contamination are from chemically active building materials and from leaks in the sewer system.

Contamination through diffuse and point sources

The introduction of urban contaminants into the aquatic environment occurs mainly through waste water, with each source being of variable composition. Most contaminants originate as effluent from the waste water treatment plants which can be treated as essentially point source discharges into rivers. A significant proportion of waste water input also originates from leakage of waste water systems (5-20\% of the waste water dry weather flow; Rutsch et al. 2006). At the small scale, these are also point sources. In the case of many leaks, as found, e.g., in older systems, these sewers can be defined as the urban line sources (Leschik et al. 2009a). Over large areas, they are recognized as diffuse contaminant sources which imply that cities are always potential contaminant sources for the local water resources as well as for downstream communities and ecosystems (Kennedy et al. 2007). Especially, worrisome are urban contaminants in megacities which have no alternative to the use of urban aquifers as a drinking water source (e.g. Beijing, China; Zhang and Kennedy 2006).

Due to their chemical polarity, pharmaceuticals are poorly retained in sewage sludge and natural sediments of surface water bodies (Reinstorf et al. 2008). Therefore, they can also contaminate groundwater by sewer leakages or bank infiltration of contaminated surface water. On the other hand, most endocrine disrupting compounds tend to be hydrophobic and enriched in organic material (biofilms) and sediments. In this case, waste water treatment plant effluent is the most important pathway and typical concentrations can be found in the range of $\mu \mathrm{g} \mathrm{L}^{-1}$ in surface water bodies with large fractions of waste water (e.g., Ternes 1998; Reinstorf et al. 2008).

Naturally, the release of PPCPs by humans in urban areas is regional but the intensity has significant local-scale differences. Examples include the use of pharmaceuticals in hospitals or the larger quantities of applied of personal care products in densely populated areas in comparison to single home communities.

Overall, the temporally and spatially variable inputs from different waste water sources combined with the extremely variable transport pathways result in highly variable concentrations and load patterns in all receiving waters within urban environments (Musolff 2009). Although we have made considerable progress over the last few decades in investigative techniques, risk analysis and remediation in industrially contaminated areas (e.g. Heidrich et al. 2004; Schirmer et al. 2006), efficient investigation, monitoring and remediation strategies for highly variable contamination of urban areas are, to date, still widely lacking (Schirmer et al. 2007).

\section{Materials and methods}

Indicator substances

A large variety of parameters are related to anthropogenically induced activities in urban areas. We have selected suitable indicators for studying the sources, transport and distribution, and the transfer processes of water-bound micropollutants in urban surface water and groundwater. The selected indicators are evaluated for their applicability to reflect the various impacts on the urban water cycle under the given hydrogeological conditions and urban structures. The criteria for the chosen indicators are the following:

- Indicators should be typical for special kinds of contaminant pathways, e.g. from sewer leakages to groundwater, from waste water treatment plant (WWTP) effluents or from CSOs.

- To investigate their spread in the environment, they should be persistent. The potential for biodegradation can be investigated by considering additional nonpersistent indicators.

- They should be transported with the flow of water, i.e. they should be mobile.

- Indicators should be of concern in the health of the population or the ecosystem, or they should reflect the path of other chemicals which are important for human or ecosystem health.

- Analytical methods for determining concentrations should not require excessive effort in the laboratory.

The chosen indicators of nitrate, sulphate, chloride, boron, the stable isotopes of hydrogen, nitrogen, oxygen, sulphur and boron, as well as the xenobiotics bisphenol $\mathrm{A}$ (BPA), carbamazepine (CBZ), nonylphenol (NP), Galaxolide $^{\circledR}$ (HHCB), Tonalide ${ }^{\circledR}$ (AHTN), caffeine (CAF), and gadolinium (GD), all helped to assess fluxes of urban substances and to assess urban effects on water quality. In view of the selection criteria, the indicators and important parameters are shown in Table 1 including their original usage.

We used multivariate statistical methods to evaluate the different substances with respect to their usability as unique indicators for different urban sources (Musolff et al. 2007, 2010a). The xenobiotics BPA, CBZ, HHCB, AHTN and GD can be attributed to treated and untreated waste water sources. CBZ and GD are persistent in the WWTP as well as in the aquatic environment (Clara et al. 2004, Massmann et al. 2008). CAF was found to be a 
Table 1 Selected indicators in the urban water cycle, their application, occurrence and effect

\begin{tabular}{|c|c|}
\hline Indicator compound & Application/occurrence/effect \\
\hline Bisphenol A (BPA) & Component in plastics (resins, poly-carbonate); endocrine disruptor (estrogenic) \\
\hline Carbamazepine (CBZ) & Antiepileptic drug \\
\hline Nonylphenol (NP) & Constituent of detergents, anti-oxidants; endocrine disruptor interaction with estrogenic receptor \\
\hline Galaxolide $^{\circledR}$ (HHCB) & Fragrance, chemo sensitizer \\
\hline Tonalide $^{\circledR}($ AHTN $)$ & Fragrance, chemo sensitizer \\
\hline Caffeine (CAF) & Stimulant, indicator for untreated waste water inputs \\
\hline Gadolinium (Gd); Gd-DTPA & Contrast component in human medicine; geogenic occurrence as rare earth element \\
\hline Nitrate $\left(\mathrm{NO}_{3}{ }^{-}\right)$ & Fertilizers, component of waste water \\
\hline Sulphate $\left(\mathrm{SO}_{4}^{2-}\right)$ & $\begin{array}{l}\text { Geogenic: mineral and drinking water, salt water, brines; anthropogenic: waste water, landfill } \\
\text { drainage }\end{array}$ \\
\hline Chloride $\left(\mathrm{Cl}^{-}\right)$ & $\begin{array}{l}\text { Geogenic: mineral and drinking water, salt water, brines; anthropogenic: waste water, road de-icing, } \\
\text { landfill drainage }\end{array}$ \\
\hline Boron (B) & Ingredient in detergents \\
\hline Hydrogen isotopes ${ }^{2} \mathrm{H} / \mathrm{H}$ & Water and water-related compounds; sources, origin, transport, mixing processes \\
\hline Nitrogen isotopes ${ }^{15} \mathrm{~N} /{ }^{14} \mathrm{~N}$ & Air, N-bearing compounds (bound, dissolved); origin, degradation, mixing processes \\
\hline Oxygen isotopes ${ }^{18} \mathrm{O} /{ }^{16} \mathrm{O}$ & Water, air, rocks/sediments; origin, transport, mixing processes \\
\hline Sulphur isotopes ${ }^{34} \mathrm{~S} /{ }^{32} \mathrm{~S}$ & Minerals, S-bearing compounds: origin, degradation, acidification \\
\hline Boron isotopes ${ }^{11} \mathrm{~B} /{ }^{10} \mathrm{~B}$ & Borates, detergents; origin, transport \\
\hline
\end{tabular}

good indicator for untreated waste water inputs (e.g. $\mathrm{CSO}$ ), since it is nearly completely removed in the WWTP (see also Buerge et al. 2003). Together with HHCB and AHTN, its rapid removal in warm surface waters has to be kept in mind (Musolff et al. 2009). NP is released via waste water sources but is also present in rural runoff due to its use as a surfactant in pesticide mixtures. NP and BPA were found to be ubiquitously present in urban groundwater in the upper $\mathrm{ng} \mathrm{L}^{-1}$-range (Musolff et al. 2009). We attribute this contamination to the input of waste water by sewer leakages. Nitrate is not a unique indicator for urban waste water sources, since it may originate from either waste water (from $\mathrm{NH}_{4}$ ) or from fertilizers. Fertilizers from rural upstream water resources may also hinder the interpretation of nitrogen contamination. Sulphate may originate from geogenic sources as well as from waste water and leachate from construction waste. Boron can be a good indicator for waste water but can also have geogenic sources. In the study area of Leipzig, sulphate and boron were linked to industrial leachates and could not be connected with other waste water indicators. Thus, for nitrate, sulphate and boron, additional stable isotope data would be needed to distinguish their potential sources.

Sampling and sample preparation

Although some xenobiotics can be easily measured in the laboratory, the analyses include a large degree of uncertainty due to the very low concentrations and high spatial and temporal variability. In the following, we briefly summarize the sampling, sample preparation and analytical methods.

Surface water and waste water samples were obtained using grab sampling. Groundwater sampling was performed using submerged pumps following the German DVWK protocol (DVWK 245 1997). Samples for xenobiotic analysis (1 L each) were placed in amber glass bottles, closed with a glass stopper and stored in a dark and cool environment. Preparation methodology and chemical analysis of these samples are described below.

Solid phase extraction (SPE) was used to enrich the target compounds from the water samples. Before being concentrated, samples (1 L, pH at about 7) were filtered through a glass fibre filter with a particle retention size of $1 \mu \mathrm{m}$ and spiked with the internal standards (4-n-nonylphenol (Supelco) and 13C12-BPA (Cambridge Isotope Labs), 100 ng each).

The filtrates were adjusted to $\mathrm{pH} 2$ and concentrated by SPE using a sorbent mixture (C18 and Lichrolut ${ }^{\circledR} \mathrm{EN}$, Merk) preconditioned with methanol and water. After application of the water sample, the sorbent was dried under inert gas and finally eluted with methanol and acetone. After evaporation of the solvent to a final volume of $300 \mu \mathrm{L}$, a cleanup at silica gel was accomplished using a mixture of acetone and hexane. The evaporation of the solvent to a volume of $200 \mu \mathrm{L}$ gave the final sample for $\mathrm{GC}-\mathrm{MS}$ analysis. 
GC-MS-analyses of xenobiotics

The analyses of the marker compounds caffeine, Galaxolide $^{\circledR}$, Tonalide ${ }^{\circledR}$, bisphenol A, nonylphenol and carbamazepine were performed using a Varian GC-MS (CP 3800, MS 1200) equipped with a temperature-programmable injection port. The marker compounds were obtained from either SUPELCO (Nonylphenol), Sigma/Aldrich (Galaxolide, Tonalide), Fluka (caffeine) or Cambridge Isotope Labs (Bisphenol A). The gas chromatographic separation was carried out on a $60 \mathrm{~m}$ long Zebron ZB1 capillary column of $0.25 \mathrm{~mm}$ internal diameter and $0.25 \mu \mathrm{m}$ film thickness (Phenomenex). The samples $(5-10 \mu \mathrm{L}$ each) were injected at $50^{\circ} \mathrm{C}$ by large volume injection. The GC oven program started at an initial temperature of $50^{\circ} \mathrm{C}$. Helium was used as the carrier gas in constant flow mode at $1 \mathrm{~mL} \mathrm{~min}^{-1}$. The mass spectrometer operated in a positive electron impact ionization mode at $70 \mathrm{eV}$. The GC-MS interface temperature was set at $270^{\circ} \mathrm{C}$ and the source temperature at $200^{\circ} \mathrm{C}$. A solvent delay of 8 min was used to fade out the solvent signal. The investigations utilized selected ion monitoring (SIM) for sensitive detection of the target analytes (target ions Galaxolide ${ }^{\circledR}$ : 258,243,213; Tonalide ${ }^{\circledR}$ : 258,243,159; bisphenol A: 213, 228; nonylphenol: 220,149,107, carbamazepine: 236, 193). All sample extracts were twice analyzed and after every fourth analysis a blank analysis was carried out to check carryover and memory of previous analyses. The standard mixture was measured repeatedly within every sample series.

Detection limits for the groundwater samples are $0.2 \mathrm{ng} \mathrm{L}^{-1}$ for Galaxolide ${ }^{\circledR}$ and Tonalide ${ }^{\circledR}, 1 \mathrm{ng} \mathrm{L}^{-1}$ for bisphenol A, and $2 \mathrm{ng} \mathrm{L}^{-1}$ for carbamazepine. For surface water, detection limits are $1 \mathrm{ng} \mathrm{L}^{-1}$ for Galaxolide ${ }^{\circledR}$ and Tonalide $^{\circledR}, 5 \mathrm{ng} \mathrm{L}{ }^{-1}$ for carbamazepine and $10 \mathrm{ng} \mathrm{L}^{-1}$ for bisphenol A, nonylphenol.

\section{Isotopic analyses}

The analyses for the stable isotope indicators of hydrogen, nitrogen, oxygen, sulphur and boron were performed using gas chromatography with mass spectrometry (GC-MS). Gas chromatographic separation was performed with a "HP 6890 series" gas chromatograph equipped with a fused silica capillary column "HP-5MS", $30 \mathrm{~m} \times$ $0.25 \mathrm{~mm}$ id, film thickness: $0.25 \mu \mathrm{m}$ (Agilent Technologies, San José, USA). The mass spectrometric analysis was completed with a mass selective detector 5973 (Agilent Technologies, San José, USA) operated with electron impact (EI, $70 \mathrm{eV}$ ) as well as negative chemical ionization (NCI) using methane as the reactant gas. $1 \mu \mathrm{L}$ was injected at $280^{\circ} \mathrm{C}$ injection temperature. The GC temperature program started at $50^{\circ} \mathrm{C}$ which was held for $1 \mathrm{~min}$, then the oven was heated to $280^{\circ} \mathrm{C}$ at a rate of $10 \mathrm{~K} / \mathrm{min}$ for $20 \mathrm{~min}$.
The transfer line was set at $280^{\circ} \mathrm{C}$, and the ion source at $200^{\circ} \mathrm{C}(\mathrm{EI}, 70 \mathrm{eV})$ and $125^{\circ} \mathrm{C}(\mathrm{NCI})$, respectively. Methane was used as the NCI reagent gas with a flow rate of $2.5 \mathrm{ml} /$ $\min$.

Inorganic analyses

Nitrate, sulphate, chloride and boron were chosen as inorganic indicators in the urban water cycle. Nitrate was determined by the salicylic acid method according to Bachhausen et al. (1985). The anions sulphate and chloride were analysed by ion chromatography (Ion Chromatograph DX 120 equipped with a Ion Pac CS12A $4 \times 250 \mathrm{~mm}$ for cations, and ICS 2000, DIONEX equipped with a Ion Pac AS $11 \mathrm{HC}$ column, $250 \times 2 \mathrm{~mm}$ for anions). For detailed information on all inorganic analyses, the reader is referred to Martienssen et al. (2006).

\section{Hydrogeological investigation and monitoring in urban areas}

General considerations

As mentioned above, contaminant occurrence in urban areas can be extremely variable, both temporally and spatially. This calls for new, more efficient investigation and monitoring strategies. In most cases, point measurements of contaminant concentrations at discrete times in selected monitoring wells usually do not allow drawing conclusions concerning contaminant fluxes in the urban areas. Therefore, flux calculations are necessary to perform a meaningful risk analysis and to select viable remediation measures (see also Kübert and Finkel 2006; Rein et al. 2009).

Investigation and monitoring the influence of waste water on an urban system must consider the respective temporal and spatial scales. The temporal scale includes the acute and cumulative nature of the inputs, while the spatial scale has to account for the spatial extent of the inputs on the water bodies. Acute inputs act fast, within minutes for example, during waste water discharge by CSOs. Cumulative loads result from gradual changes in the water bodies or after critical threshold values are reached. A typical example for a cumulative load is the release of nutrients and toxins from sediments and soils.

A number of research projects have been initiated over the past few years to investigate problems associated with the urban water flow, as well as to study contaminants and their interrelations as mentioned above. In these projects, qualitative as well as quantitative methods were applied. The qualitative methods were mainly used to investigate the contaminant concentration patterns to detect the urban 
influence (e.g., Grischek et al. 1996; Sacher et al. 2001; Massmann et al. 2006). The quantitative methods are related more towards mass flux calculations. Various research teams have investigated several aspects, including urban groundwater recharge (e.g., Lerner 2002) and the interrelation between sewer systems and groundwater (e.g., Ellis and Revitt 2002). More recent work relates to integral approaches to describe urban effects using well-known contaminants, such as polycyclic aromatic hydrocarbons (PAHs), nitrogen, phosphorus and boron (e.g., Wolf et al. 2006) or new contaminants such as PPCPs with low concentrations (e.g., Wolf et al. 2006; Strauch et al. 2008).

\section{Application of selected investigation technologies}

To characterize urban aquifers, we adapted various investigation methods including direct push technology, while contaminant mass fluxes from line sources were determined using IPTs. The direct push technology, e.g., Geoprobe $^{\circledR}$, is an example of a spatial and temporal investigation and monitoring method with high resolution. This is an interesting alternative or addition to conventional investigation techniques such as drilling of monitoring wells in the subsurface infrastructure zone of urban areas. With a high mobility and comparably fast data collection, spatial changes in subsurface structure (hydraulic conductivity, porosity) as well as contaminant distribution and other relevant parameters $(\mathrm{pH}$, redox conditions, oxygen content, temperature etc.) can be measured in great detail and much more efficiently than was previously possible. We used direct push techniques in the study area of Leipzig to install observation wells for groundwater sampling and head measurements as well as for the estimation of hydraulic conductivity in the shallow aquifer. This information was used in numerical models for determining the water balance and for the IPTs.

An additional example of spatially and temporally integrated investigation and monitoring methods is the IPT. The IPT method addresses the issue of heterogeneity of the contaminant distribution in the subsurface (Bauer et al. 2004; Bayer-Raich et al. 2004). This method consists of monitoring one or more pumping wells along a control plane perpendicular to the mean groundwater flow direction. The wells are operated with a constant discharge for a time period of up to several days. During pumping, concentrations of target contaminants are sampled in the pumped groundwater. From the concentration time series, contaminant mass flow rates through a predefined control plane and the representative average contaminant concentration along this control plane can be estimated. The method provides integrated measurements over a large groundwater volume and is, therefore, less sensitive to effects of the subsurface heterogeneity and the contaminant distribution than point measurements. However, the disposal of large volumes of contaminated groundwater that are pumped out of the wells during the test can be problematic. We used the IPT method at two locations in the study area of Leipzig to derive contaminant mass fluxes from different urban line sources.

With the examples of new investigation and monitoring technologies introduced herein, it will be possible to more efficiently obtain hydrogeological and hydrochemical data in urban areas.

\section{Results and discussion}

Over a period of 7 years, we have made extensive measurements of xenobiotic concentrations in the surface and groundwater within the city of Halle/Saale. Since the concentrations often varied considerably over time, we decided to calculate average mass fluxes by deriving a complete mass balance (Fig. 1). The results showed that surface water loads of Galaxolide ${ }^{\circledR}(+182 \%)$, Tonalide ${ }^{\circledR}$ $(+364 \%)$, nonylphenol $(+26 \%)$ and carbamazepine $(+21 \%)$ increase significantly within the city (Reinstorf et al. 2008). It can be concluded that the city influences the amount of these micropollutants in the surface water and also in groundwater. In contrast, the load of bisphenol A (industrial chemical, endocrine disrupting substance; $+2 \%$ ) did not change significantly. It is known that bisphenol A can be degraded biologically to such an extent that its degradation along a river reach of about $20 \mathrm{~km}$ is probable (Ying et al. 2008). We thus assume herein that degradation processes during passage of bisphenol A through the hyporheic zone or within the river masks the influence of the city with regard to this substance.

The calculated "corresponding concentrations in the diffuse groundwater inflow" are similar in magnitude to the maximum measured concentrations in the river, but a comprehensive explanation and assessment of the sources and transport processes leading to this magnitude of concentrations are not yet possible. Further investigations are ongoing using isotopic $\left(\delta^{18} \mathrm{O}, \delta^{2} \mathrm{H}, \delta^{34} \mathrm{~S}_{-} \mathrm{SO}_{4}\right)$ and chemical tracers (boron) (Osenbrück et al. 2007).

Based on the results from the city of Halle/Saale, a further study was conducted in the city of Leipzig to characterize xenobiotic occurrence and mass fluxes in urban ground- and surface water (Musolff et al. 2007). Here, the investigations relied on the watershed-sewershed approach (Schirmer et al. 2007). The study area was carefully chosen to ensure matching catchments of waste water as a source for xenobiotic contaminants and groundwater as well as surface water as recipients. Thus, a combined water and contaminant mass balance can be derived. This study relies on a monitoring of xenobiotics 
Fig. 1 Inlet and outlet mass fluxes in the surface water (Saale River) of the city of Halle/Saale (Germany)

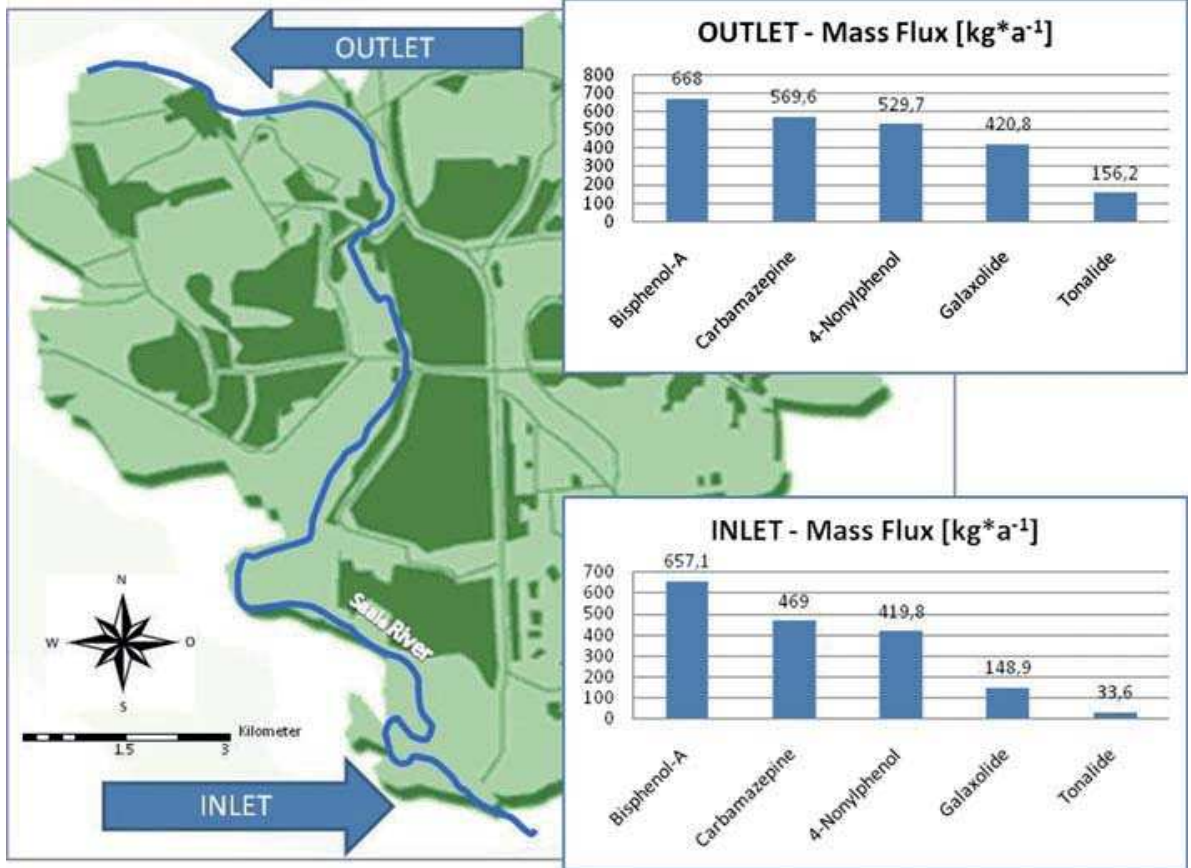

over the course of 1 year, taking potentially seasonal effects into account.

With the help of statistical methods, we were able to characterize the xenobiotic occurrence in the urban water compartments. Concentrations in the receiving surface waters were found to be generally higher than in the WWTP effluents, suggesting additional intermittent sources of untreated waste water such as CSOs. Principal component analysis of the surface water samples suggests a connection between concentrations of caffeine, Galaxolide ${ }^{\circledR}$ and Tonalide ${ }^{\circledR}$ with water temperature (Musolff et al. 2010a). On the basis of surface water loads and water temperature, a rapid removal of these substances in times of higher water temperature could be demonstrated (Musolff et al. 2009). In groundwater, the spatial and temporal concentration variability was found to be high. Results of the principal component analysis compared well to the surface water samples. Here, we assume degradation processes are one of the major reasons for the high variability in groundwater (Musolff 2009).

In a further step, models of soil water/groundwater recharge, groundwater flow, CSOs and the interaction of groundwater with the sewage system were combined to derive an annual water balance of the watershed. The sewage system was found to interact with the shallow groundwater in both directions depending on the variable groundwater head and position of the sewer sections. By combining the water balance with the concentration measurements, an annual xenobiotic mass flux balance was derived. The pathways of treated waste water, CSOs and groundwater discharge were also compared and evaluated (Musolff et al. 2010b). WWTP effluents are the most important pathway of xenobiotic release from the sewershed. Depending on the persistence of the studied xenobiotics, groundwater discharge (for nonylphenol and bisphenol A) and CSOs (caffeine, nonylphenol and bisphenol A) contribute a significant part of the release (Fig. 2).

Finally, sewer leakages were quantified on the basis of the concentrations of bisphenol A and carbamazepine in the source waste water and in the receiving groundwater. Approximately $9.9-13.0 \%$ of the waste water's dry weather discharge was lost to the groundwater (Musolff et al. 2010b).

In an ongoing study, a new monitoring approach to estimate exfiltration mass flow rates per unit length $M_{\text {line }}$ source (mass flux line source) of indicator substances from urban line sources (e.g. leaky sewers) was developed in the city of Leipzig. A leaky sewer (Leschik et al. 2009a) and a CSO-influenced urban stream (Leschik et al. 2009b) were investigated in detail with a monitoring approach consisting of two IPT wells upstream and two IPT wells downstream of a line source section (Fig. 3). The corresponding isochrones for each sampling time were calculated with a particle tracking tool and a numerical groundwater model. Evaluation of the concentration-time series with a transient inversion algorithm (Bayer-Raich et al. 2004), which is implemented in the program code CSTREAM, yielded mass fluxes $M_{\mathrm{CP}}$ through control planes (CP) in the groundwater. The estimation of $M_{\text {line source }}$ values with $M_{\mathrm{CP}}$ 
Fig. 2 Distribution of xenobiotic loads from the sewershed in the city of Leipzig via the WWTP effluents, combined sewer overflows (CSO) and groundwater discharge out of the sewershed boundaries. The total load for each component was scaled to $100 \%$

Fig. 3 Schematic overview on the estimation of mass fluxes from urban line sources by the operation of integral pumping tests (IPTs). The IPTs are situated along the control planes CP 1 and CP 2 up- and downstream of the urban line source. The example IPT concentration-time series for nitrate and caffeine (gray upstream of the line source and black downstream of the line source) originate from the investigation of an urban stream in Leschik et al. (2009b). For the example concentration-time series $M_{\text {line source }}$ values of $749-924 \mathrm{mg} \mathrm{m}^{-1} \mathrm{~d}^{-1}$ for nitrate and $0-6.5 \mu \mathrm{g} \mathrm{m}^{-1} \mathrm{~d}^{-1}$ for caffeine were obtained
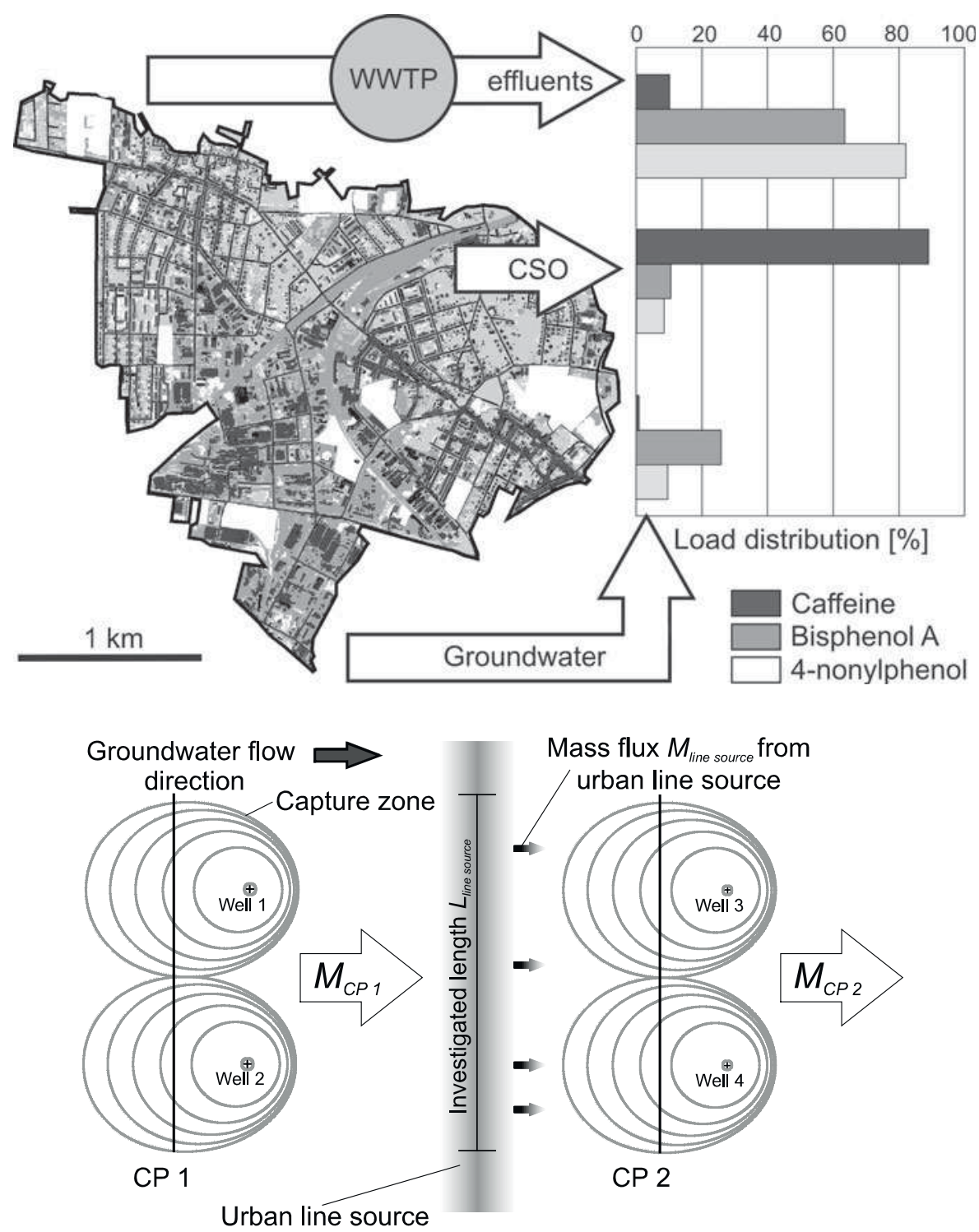

$M_{\text {line source }}=\left(M_{C P 1}-M_{C P 2}\right) L_{\text {line source }}{ }^{-1}$

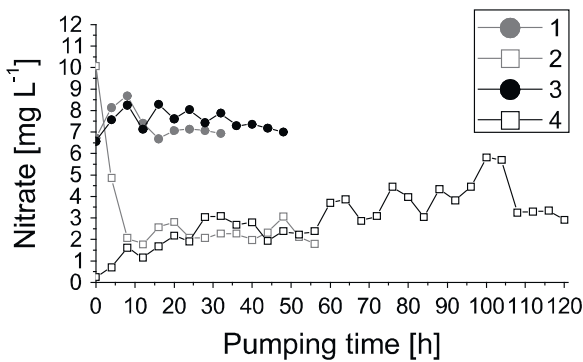

values is described in Fig. 3. If $M_{\mathrm{CP}}$ values remained stable or decreased downstream of the target section, $M_{\text {line source }}$ values could not be provided.

The results from the investigation of the leaky sewer and the urban stream show that these line sources can be an important source of the inorganic compounds $\mathrm{B}, \mathrm{Cl}^{-}$,
$\mathrm{NO}_{3}{ }^{-}$and $\mathrm{SO}_{4}{ }^{2-}$, because $M_{\text {line source }}$ values in the range of 0-47.3 $\mathrm{g} \mathrm{m}^{-1} \mathrm{~d}^{-1}$ were obtained for these compounds. The $M_{C P}$ values of the investigated micropollutants caffeine, nonylphenol, bisphenol A and Tonalide ${ }^{\circledR}$ generally decreased or remained stable downstream of the line sources. This implies that attenuation processes (e.g. 
sorption or degradation) are occurring in the unsaturated zone below the line sources and in the groundwater. Attenuation processes in the colmation layers of sewer leaks or in the streambed of the losing stream are also possible. An increased $M_{C P}$ of micropollutants downstream of the urban stream (Leschik et al. 2009b) could only be identified in one case for caffeine $\left(M_{\text {line source value of }}\right.$ $\left.6.5 \mu \mathrm{g} \mathrm{m}^{-1} \mathrm{~d}^{-1}\right)$.

The new monitoring approach, which relies on IPTs, provides detailed information about the influence of urban line sources on the groundwater composition in urban aquifers. The application can include different target substances and accounts for site-specific conditions (e.g. variable aquifer properties or different line source characteristics). The obtained $M_{\text {line source values can be used as }}$ input data for transport models in urban areas. Due to the significant effort required during the operation of the IPT wells and for sample analysis in the laboratory, the IPT monitoring approach is not suitable to survey a complete line source network. The applicability of the line source monitoring approach also depends on low background concentrations and strong water exfiltration from the target section. Due to dilution in the groundwater and during pumping, a strong concentration difference between upstream groundwater and the potential source is needed. The eight operated IPT wells at the two field sites were not enough to estimate detailed concentration differences between groundwater and the source that are necessary to obtain reliable $M_{\text {line source }}$ values. Potential concentration fluctuations in the wastewater have only a limited influence on the exfiltration from urban line sources because sediments or biofilms attenuate these fluctuations by sorption (Ort and Gujer 2008).

\section{Conclusions}

To objectively and accurately estimate contaminant concentrations and their effects on urban aquifers is a challenge and requires understanding the input, transport and degradation processes at the local scale with a simultaneous perspective at the catchment scale. Due to aquifer heterogeneity combined with extended subsurface infrastructure and a wide contaminant spectrum in urban areas, urban groundwater resources have unique characteristics that hamper assessment of its quality as well as quantity. Water and contaminant pathways are highly variable in time and space, due in part to sewage systems which are closely linked with groundwater (sewer leakages to the groundwater and groundwater exfiltration to the sewage system) as well as with surface water (WWTP effluents and combined sewer overflows).

To understand the variable input pathways of contaminants in urban water resources, we used an indicator approach. Several substances were chosen to represent different contaminant sources and pathways. Here, we used waste water-borne xenobiotics as well as inorganic substances and their isotopic composition. None of the indicators fit all the stated selection criteria. Xenobiotics can be unique in originating from waste water sources but require an extensive chemical analysis. The variability of these substances demands a large number of samples which some laboratories may not be able to accommodate. On the other hand, inorganic indicators are easy to measure but can have multiple anthropogenic as well as geogenic sources. Here, a combination of both types of indicators is useful. Based on our findings, we conclude that the following substances are most suitable: carbamazepine, nonylphenol and bisphenol A for the assessment of waste water inputs to groundwater, and caffeine, Galaxolide ${ }^{\circledR}$ and Tonalide ${ }^{\circledR}$ for waste water inputs to surface waters. In groundwater, measurements of nitrate, sulphate, boron and its isotopes proved to be useful in assessing groundwater deterioration by waste water and other sources.

Identification of anthropogenic impacts on urban waters is often difficult or even impossible with single concentration measurement campaigns alone. A more promising approach is to determine contaminant mass fluxes as reported here, although these methods are, by far, more expensive. With contaminant mass fluxes, we are able to understand input and degradation at smaller scales as shown with the integral pumping test methods. On the larger sewershed-scale, mass fluxes help to identify the different input pathways and their importance. Here, water fluxes have to be determined using a model that integrates groundwater, surface water and soil water.

Our findings in the study areas of the cities of Halle and Leipzig provide a sound basis for further refinement and integration of investigation and monitoring technologies and strategies. In the following chapter, we give some ideas for further development.

\section{Future development}

For industrially contaminated areas, a large number of investigation and monitoring strategies have been developed over the past three decades. Although these approaches provide a good basis, they have to be further developed for the unique urban hydrogeological environments (Schirmer et al. 2007). It is clear from current qualitative analyses and preliminary quantification that a forecast of contaminant behaviour in urban areas requires a detailed process understanding. This cannot be derived from lab experiments or phenomenological analyses at the catchment scale. Therefore, we have established the experimental research platform Water- and Sewershed 
Study of Environmental Risk in Leipzig (WASSER Leipzig). By installing measuring equipment at the interfaces between the unsaturated and saturated zone as well as between ground- and surface water, in situ contaminant fate and transport processes can be quantified in the centimetre and metre range (Musolff et al. 2007).

Furthermore, the large number of samples required to assess heterogeneous urban water contamination calls for an alternative to the conventional snapshot-sampling. Over the past few years, the technique of passive sampling has been extensively refined and a variety of devices has evolved. In general, contaminants are collected by diffusion and/or sorption over extended periods of time. After sampling using these devices, contaminants are removed from the receiving phases or whole samplers by solvent extraction or thermodesorption and analysed chemically. The state-of-the-art of passive sampling techniques is summarized in a review article by StuerLauridsen (2005). Further developments of passive sampling devices have allowed a combined chemical and toxicological analysis of the samples (Bopp et al. 2007), and combined contaminant and water flux measurements (e.g., Hatfield et al. 2004). The accumulation of contaminants over an entire sampling period provides time-averaged measurements which are less sensitive to short-term fluctuations. Furthermore, very low contaminant concentrations can be detected in this way. Long-term monitoring using passive samplers is time- and cost-efficient, since only a few field trips and sample analyses are required (Martin et al. 2003; Bopp et al. 2007).

To investigate the spatial and temporal contaminant source functions and input distribution, trends and research in social sciences should also be included. Through an analysis and evaluation of user-specific resource use and needs, conclusions about likely patterns and trends concerning the release of special pharmaceuticals and life-style products can be derived.

Future projects to investigate the water cycle in urban areas should include strategies to minimize contaminant input. Furthermore, sustainable remediation technologies need to be developed for urban contamination of groundand surface water. Urban areas are always a potential contaminant source for downgradient communities and ecosystems. Nevertheless, urban aquifers are often sources for drinking water production, especially in megacities (Zhang and Kennedy 2006). Therefore, we must improve our effort to protect urban aquifer resources. This is especially important due to the fact that megacities have developed in many parts of the world and their number and extent is growing. There is a substantial need to move more towards a precautionary and preventative approach for urban water protection. Close collaboration between research and practise is thereby essential.
Acknowledgments We thank our colleagues from the UFZ-integrated project "Micropollutants in water and soil in the urban environment". We also would like to thank two anonymous reviewers who helped to strengthen the manuscript.

\section{References}

Bachhausen P, Buchholz N, Hartkamp H (1985) Determination of nitrate by means of cromotropic acid. Fresenius Z. Anal. Chem. 320:490-493

Bauer S, Bayer-Raich M, Holder T, Kolesar C, Müller D, Ptak T (2004) Quantification of groundwater contamination in an urban area using integral pumping tests. J Contam Hydrol 75:183213

Bayer-Raich M, Jarsjö J, Liedl R, Ptak T, Teutsch G (2004) Average contaminant concentration and mass flow in aquifers from timedependent pumping well data: analytical framework. Water Resour Res 40:W08303

Bopp SK, MacLachlan MS, Schirmer K (2007) Passive sampler for combined chemical and biological long-term monitoring of groundwater-the Ceramic Toximeter. Environ Sci Technol 41(19):6868-6876

Buerge IJ, Poiger T, Müller MD, Buser HR (2003) Caffeine, an anthropogenic marker for wastewater contamination of surface waters. Environ Sci Technol 37(4):691-700

Clara M, Strenn B, Kreuzinger N (2004) Carbamazepine as a possible anthropogenic marker in the aquatic environment: investigations on the behaviour of carbamazepine in wastewater treatment and during groundwater infiltration. Water Res 38(4):947-954

DVWK (1997) Tiefenorientierte Probennahme aus Grundwassermessstellen. DVWK-Merkblatt 245 Wirtschafts- und Verlag-Gesellschaft Gas und Wasser, Bonn

Ellis JB, Revitt DM (2002) Sewer losses and interactions with groundwater quality. Water Sci Technol 45:195-202

Grischek T, Nestler W, Piechniczek D, Fischer T (1996) Urban groundwater in Dresden, Germany. Hydrogeol J 4:48-63

Hatfield K, Annable M, Cho J, Rao PSC, Klammler H (2004) A direct passive method for measuring water and contaminant fluxes in porous media. J Contam Hydrol 75:155-181

Heberer T (2002) Tracking persistent pharmaceutical residues from municipal sewage to drinking water. J Hydrol 266:175-189

Heidrich S, Schirmer M, Weiss H, Wycisk P, Grossmann J, Kaschl A (2004) Regionally contaminated aquifers-toxicological relevance and remediation options (Bitterfeld case study). Toxicolology 205:143-155

Kennedy CA, Cuddihy J, Engel Yan J (2007) The changing metabolism of cities. J Ind Ecol 11(2):43-59

Kübert M, Finkel M (2006) Contaminant mass discharge estimation in groundwater based on multi-level point measurements: a numerical evaluation of expected errors. J Contam Hydrol 84(1-2):55-80

Lerner DN (2002) Identifying and quantifying urban recharge: a review. Hydrogeol J 10:143-152

Leschik S, Musolff A, Martienssen M, Krieg R, Bayer-Raich M, Reinstorf F, Strauch G, Schirmer M (2009a) Investigation of sewer exfiltration using integral pumping tests and wastewater indicators. J Contam Hydrol 110(3-4):118-129

Leschik S, Musolff A, Krieg R, Martienssen M, Bayer-Raich M, Reinstorf F, Strauch G, Schirmer M (2009b) Application of integral pumping tests to investigate the influence of a losing stream on groundwater quality. Hydrol Earth Syst Sci 13(10):1765-1774

Luckenbach T, Epel D (2005) Nitromusk and polycyclic musk compounds as long-term inhibitors of cellular xenobiotic defense 
systems mediated by multidrug transporters. Environ Health Perspect 113(1):17-24

Martienssen M, Fabritius H, Kukla S, Balcke GU, Hasselwander E, Schirmer M (2006) Determination of natural occurring MTBE biodegradation by analysing metabolites and biodegradation products. J Contam Hydrol 87(3-4):37-53

Martin H, Patterson BM, Davis GB, Grathwohl P (2003) Comparative field trial of time-integrated aqueous contaminant monitoring with ceramic dosimeters and conventional water sampling. Environ Sci Technol 37:1360-1364

Massmann G, Greskowiak J, Dünnbier U, Zuehlke S, Knappe A, Pekdeger A (2006) The impact of variable temperatures on the redox conditions and the behaviour of pharmaceutical residues during artificial recharge. J Hydrol 328:141-156

Massmann G, Sültenfuss J, Dünnbier U, Knappe A, Taute T, Pekdeger A (2008) Investigation of groundwater a residence times during bank filtration in Berlin: multi-tracer approach. Hydrol Process 22(6):788-801

Musolff A (2009) Micropollutants-challenges in hydrogeology. Hydrogeol J 14(4):763-766

Musolff A, Leschik S, Reinstorf F, Strauch G, Möder M, Schirmer M (2007) Xenobiotika im Grundwasser und Oberflächenwasser der Stadt Leipzig (Xenobiotics in groundwater and surface water in the city of Leipzig). Grundwasser 12(3):217-231

Musolff A, Leschik S, Möder M, Strauch G, Reinstorf F, Schirmer M (2009) Temporal and spatial patterns of micropollutants in urban receiving waters. Env Pollut 157(11):3069-3077

Musolff A, Leschik S, Schafmeister M-T, Reinstorf F, Strauch G, Krieg R, Schirmer M (2010a) Evaluation of xenobiotic impact on urban receiving waters by means of statistical methods. Water Sci Technol 62(3):684-692

Musolff A, Leschik S, Reinstorf F, Strauch G, Schirmer M (2010b) Micropollutant loads in the urban water cycle. Environ Sci Technol 44(13):4877-4883

Ort C, Gujer W (2008) Sorption and high dynamics of micropollutants in sewers. Water Sci Technol 57(11):1791-1797

Osenbrück K, Gläser H-R, Knöller K, Möder M, Wennrich R, Busch W, Reinstorf F, Schirmer M, Strauch G, Weise SM (2007) Source, transport and fate of organic micropollutants in urban groundwater underlying the city of Halle (Saale), Germany. Water Res 41(15):3259-3270

Rein A, Bauer S, Dietrich P, Beyer C (2009) Influence of temporally variable groundwater flow conditions on point measurements and contaminant mass flux estimations. J Contam Hydrol 108(3-4):118-133
Reinstorf F, Strauch G, Schirmer K, Gläser H-R, Möder M, Wennrich R, Osenbrück K, Schirmer M (2008) Mass fluxes and spatial trends of xenobiotics in the waters of the city of Halle, Germany. Environ Pollut 152(2):452-460

Rutsch M, Rieckermann J, Krebs P (2006) Quantification of sewer leakage: a review. Water Sci Technol 54(6-7):135-144

Sacher F, Lange FT, Brauch H-J, Blankenhorn I (2001) Pharmaceuticals in groundwaters: analytical methods and results of a monitoring program in Baden-Württemberg, Germany. J Chromatogr A 938:199-210

Schirmer K, Schirmer M (2008) Who is chasing whom? A call for a more integrated approach to reduce the load of micro-pollutants in the environment. Water Sci Technol 57(1):145-150

Schirmer M, Dahmke A, Dietrich P, Dietze M, Gödeke S, Richnow HH, Schirmer K, Weiß H, Teutsch G (2006) Natural attenuation research at the contaminated megasite Zeitz. J Hydrol 328(3-4):393-407

Schirmer M, Strauch G, Schirmer K, Reinstorf F (2007) Urbane Hydrogeologie-Herausforderungen für Forschung und Praxis (Urban hydrogeology-challenges for research and practice). Grundwasser 12(3):178-188

Schmitt-Jansen M, Bartels P, Adler N, Altenburger R (2007) Phytotoxicity assessment of diclofenac and its phototransformation products. Anal Bioanal Chem 387(4):1389-1396

Schwarzenbach RP, Escher BI, Fenner K, Hofstetter TB, Johnson CA, von Gunten U, Wehrli B (2006) The challenge of micropollutants in aquatic systems. Science 313:1072-1077

Strauch G, Möder M, Wennrich R, Osenbrück K, Gläser H-R, Schladitz T, Müller C, Schirmer K, Reinstorf F, Schirmer M (2008) Indicators for assessing anthropogenic impact on urban surface and groundwater. J Soil Sediments 8(1):23-33

Stuer-Lauridsen F (2005) Review of passive accumulation devices for monitoring organic micropollutants in the aquatic environment. Environ Pollut 136:503-524

Ternes TA (1998) Occurrence of drugs in German sewage treatment plants and rivers. Water Res 32:3245-3260

UN (2004) World Urbanization Prospects - the 2003 revision. United Nations, New York

Wolf L, Morris B, Burn S (eds.) (2006) Urban water Resources Toolbox-integrating groundwater into urban water management. IWA Publishing, ISBN 1843391384

Ying G-G, Tozeb S, Hannab J, Yua X-Y, Dillona PJ, Kookanaa RS (2008) Decay of endocrine-disrupting chemicals in aerobic and anoxic groundwater. Water Res 42:1133-1141

Zhang L, Kennedy C (2006) Determination of sustainable yield in urban groundwater systems: Beijing, China. J Hydrol Eng 11(1):21-28 